\title{
The novel coronavirus (COVID-19) pneumonia with negative detection of viral ribonucleic acid from nasopharyngeal swabs: a case report
}

Peiyan Zhang ${ }^{1+}$, Zhao $\mathrm{Cai}^{2+}$, Weibo $\mathrm{Wu}^{1}$, Ling Peng ${ }^{1}$, Yinfeng $\mathrm{Li}^{1}$, Chuming Chen ${ }^{1}$, Li Chen ${ }^{1}$, Jianming $\mathrm{Li}^{1}$, Mengli Cao ${ }^{1}$, Shiyan Feng ${ }^{1}$, Xiao Jiang ${ }^{1}$, Jing Yuan ${ }^{1}$, Yingxia Liu', Liang Yang ${ }^{2^{*+}}$ (D) and Fuxiang Wang ${ }^{1^{* *}}$

\begin{abstract}
Background: The novel coronavirus disease 2019 (COVID-19) outbreak started in Wuhan, Hubei, China since Dec 2019 and cases of infection have been continuously reported in various countries. It is now clear that the SARSCOV-2 coronavirus is transmissible from human to human. Nucleic acid detection is considered as the gold standard for the diagnosis of COVID-19. In this case report, we describe our experience in detection of SARS-COV-2 from a confirmed patient using nucleic acid test of bronchoalveolar-lavage fluid (BALF) samples but not nasopharyngeal swabs.

Case presentation: We present a case of severely ill SARS-COV-2 infected 46-year-old man with fever, coughing and chest tightness. We performed viral detection using his BALF samples and imaging method (CT) for confirmation. The patient received combination of interferonalfa- $1 \mathrm{~b}$ and ribavirin, lopinavir and ritonavir for antiviral treatment at different stages. Other medication was also given to him in combination for anti-inflammation, intestinal microbial regulation, phlegm elimination, liver protection and pulmonary fibrosis prevention purposes. We provided oxygen supply to him using BIPAP ventilator and high-flow humidification oxygen therapy instrument to facilitate respiration. The patient was cured and discharged.

Conclusion: This case report described an effective supportive medication scheme to treat SARS-COV-2 infected patient and emphasized the necessity of detection of the viral genome using BALF samples and its significance in the diagnosis and prognosis of the disease.
\end{abstract}

Keywords: Coronavirus, COVID-19, Pneumonia, Tracheoscopy, Bronchoalveolar-lavage fluid

\footnotetext{
* Correspondence: yang|@sustech.edu.cn; 13927486077@163.com

†Peiyan Zhang, Zhao Cai, Liang Yang and Fuxiang Wang contributed equally to this work.

${ }^{2}$ School of Medicine, Southern University of Science and Technology, Shenzhen 518055, Guangdong Province, People's Republic of China

'Shenzhen Third People's Hospital, Second Hospital Affiliated to Southern University of science and Technology, Shenzhen, Guangdong Province, China
}

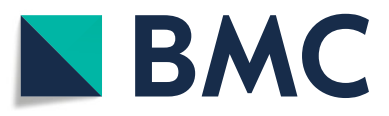

(c) The Author(s). 2020 Open Access This article is licensed under a Creative Commons Attribution 4.0 International License, which permits use, sharing, adaptation, distribution and reproduction in any medium or format, as long as you give appropriate credit to the original author(s) and the source, provide a link to the Creative Commons licence, and indicate if changes were made. The images or other third party material in this article are included in the article's Creative Commons licence, unless indicated otherwise in a credit line to the material. If material is not included in the article's Creative Commons licence and your intended use is not permitted by statutory regulation or exceeds the permitted use, you will need to obtain permission directly from the copyright holder. To view a copy of this licence, visit http://creativecommons.org/licenses/by/4.0/ The Creative Commons Public Domain Dedication waiver (http://creativecommons.org/publicdomain/zero/1.0/) applies to the data made available in this article, unless otherwise stated in a credit line to the data. 


\section{Background}

The outbreak of the novel coronavirus disease COVID19 caused by severe acute respiratory syndrome coronavirus 2 (SARS-COV-2) started in Wuhan, Hubei, China from December 2019, and has been spread out to the world [1, 2]. As of April 10, 2020, there are 83,323 confirmed cases in China among which 3346 died, while more than 1,527,482 confirmed cases in the world among which 92,532 died [3]. It is speculated that the natural hosts of SARS-COV-2 are possibly wild animals such as bats and pangolins [4,5]. However, this is still under discussion. The virus could spread from human to human through aerosol, facal-oral route and eye secretions [6-9]. Further understanding on its epidemiology, transmission mechanism and spectrum of symptoms is under continuous investigation. This case report describes the symptoms, diagnosis and treatments of one unconventional COVID-19 pneumonia case in our hospital during early period of the outbreak when having very little understanding on the virus and the infection.

\section{Case presentation}

On 23 January 2020, a 46-year-old man was transferred to our hospital with 11-days history of fever of $38^{\circ} \mathrm{C}$ and coughing. The patient permanently resides in Yili Development Zone, Xinjiang, China. He started low fever with dry cough, muscle ache and fatigue without known causes in Yili on 12 January. The patient disclosed that he had been in close contact with a person from Wuhan in Yili on 10 January and had a travel history with flights to Shanghai on 16 January 2020, from Shanghai to Ningbo on 17 January 2020, and from Ningbo to Shenzhen on January 19, 2020, without traveling or living history to Wuhan. On 18 January, there was onset of symptoms including chest tightness without chest pain and hemoptysis. Unknown medication was taken by the patient without symptomatic improvement. He was considered as a pneumonia patient and admitted to the University of Hong Kong-Shenzhen Hospital on 19 January. Results of blood gas analysis showed a $\mathrm{pH}$ of 7.445 , carbon dioxide partial pressure of $4.72 \mathrm{KPa}$ and oxygen partial pressure of $7.82 \mathrm{KPa}$. He was tested negative for influenza $\mathrm{A} / \mathrm{B}$ virus and respiratory syncytial virus (RSV), Mycoplasma pneumoniae, Cryptococcus haemolyticus antigen, Aspergillus antigen, Epstein-Barr virus capsid antigen IgM, Epstein-Barr virus DNA, Cytomegalovirus DNA and antigen IgM. He was isolated in a single ward and received oxygen support and levofloxacin treatment. On 22 January, the patient was still having fever of $38.5^{\circ} \mathrm{C}$ with chest tightness and shortness of breath. BALF was tested negative for Aspergillus, Legionella, Pneumocystis carinii, acid-fast Bacilli, Mycobacterium tuberculosis. He was diagnosed with severe bilateral community-acquired pneumonia (not excluding the possibility of COVID-19 pneumonia) and hypoxemia. Levofloxacin treatment was thus stopped and changed to combined anti-infection treatment of amoxicillin and clavulanate potassium and doxycycline. He was transferred to the Third People's hospital of Shenzhen for further treatment on 23 January. The patient has no history of other diseases, surgical trauma, food and drug allergy. There was no headache, dizziness, vomiting, abdominal pain, diarrhea, frequent urination, urgent urination, or urination pain claimed by the patient.

The results of physical examination on 23 January showed a body temperature of $36.1{ }^{\circ} \mathrm{C}$, pulse of 94 times/min, respiratory rate of 26 breaths/min and blood pressure of $127 / 87 \mathrm{mmHg}$. Clinical laboratory test results revealed negative results for mycoplasma, chlamydia, cytomegalovirus-IgM, influenza A/B virus and RSV. Throughout the whole period of hospitalization, the patient was isolated in a single ward and given $60 \mu \mathrm{g}$ of interferonalf-a1b (Beijing Tri-Prime Gene Pharmaceutical Co., Ltd., China; Shenzhen Kexing Biopharm, China) inhalation for antiviral purpose, $0.4 \mathrm{~g}$ of BioThree tablets (Huizhou Jiuhui Pharmaceutical Co., Ltd., China; Toa Pharmaceutical Co.,Ltd.Tatebayashi Plant, Japan) and $420 \mathrm{mg}$ Bifid-triple viable capsule (Inner Mongolia Shuangqi Pharmaceutical Co., Ltd., China) three times a day for regulation of intestinal microbiome, and $30 \mathrm{mg}$ mucosolvan (Boehringer Ingelheim Espana,S,A.) intravenous injection twice per day for phlegm elimination. A 3-day course of $0.5 \mathrm{~g}$ ribavirin (Jiangsu Lianshui Pharmaceutical Co., Ltd., China) intravenous injection starting from 23 January was also given to the patient in combination with Interferonalfa- $1 \mathrm{~b}$ twice a day for 3 days for antiviral treatment of RNA virus. (Fig. 2).

On 24 January, the patient was reported to have shortness of breath with respiratory rate of 38 times/min and heart rate of 90 times/min. Blood gas analysis revealed a $\mathrm{pH}$ value of 7.428 , carbon dioxide partial pressure of $43.0 \mathrm{mmHg}$, oxygen partial pressure of $64.4 \mathrm{mmHg}$, actual bicarbonate level of $28.4 \mathrm{mmol} / \mathrm{L}$, oxygen saturation of $92 \%$ and fractional concentration of inspired oxygen $\left(\mathrm{FiO}_{2}\right)$ of $41.0 \%$. (Table 1) Supplemental oxygen was applied to the patient with non-invasive BIPAP ventilator using IPAP $14 \mathrm{cmH}_{2} \mathrm{O}$ and EPAP $7 \mathrm{cmH}_{2} \mathrm{O}$ with oxygen concentration of $45 \%$. His respiratory rate was 16 times/ min after receiving oxygen supplement. Shortness of breath was gradually relieved and patient's oxygen saturation values of peripheral blood reached 99 to $100 \%$. Routine blood test revealed a white blood cell count of $5.61 \times 10^{9} / \mathrm{L}$ with $80.40 \%$ neutrophil and $14.80 \%$ lymphocyte, hemoglobin concentration of $158 \mathrm{~g} / \mathrm{L}$, platelet count of $207 \times 10^{9} / \mathrm{L}$ (Table 1 ) and erythrocyte sedimentation rate $(\mathrm{ESR})$ of $71 \mathrm{~mm} / \mathrm{h}$. Biochemical test results showed an elevated D-Dimer (diffuse intravascular 


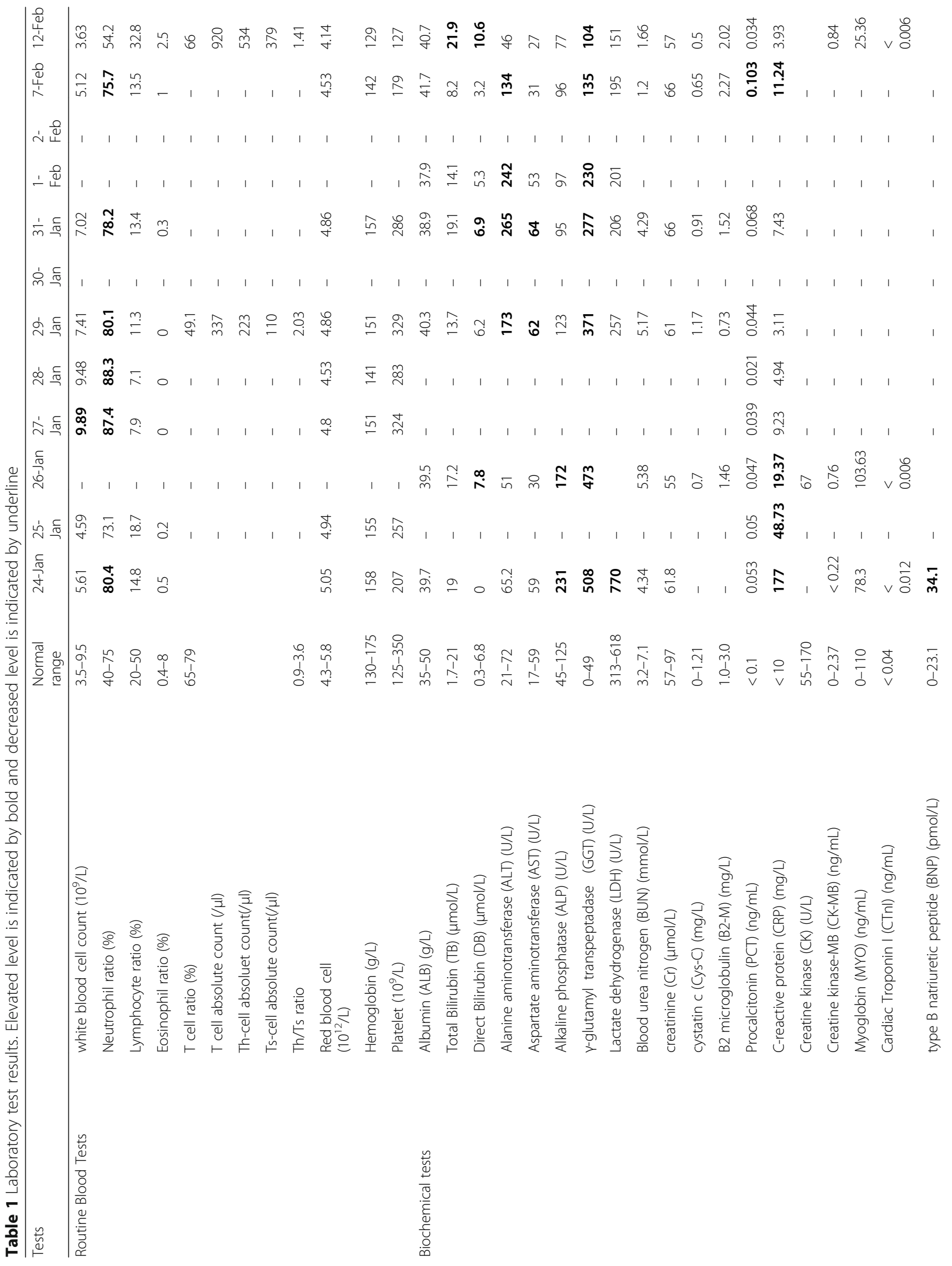




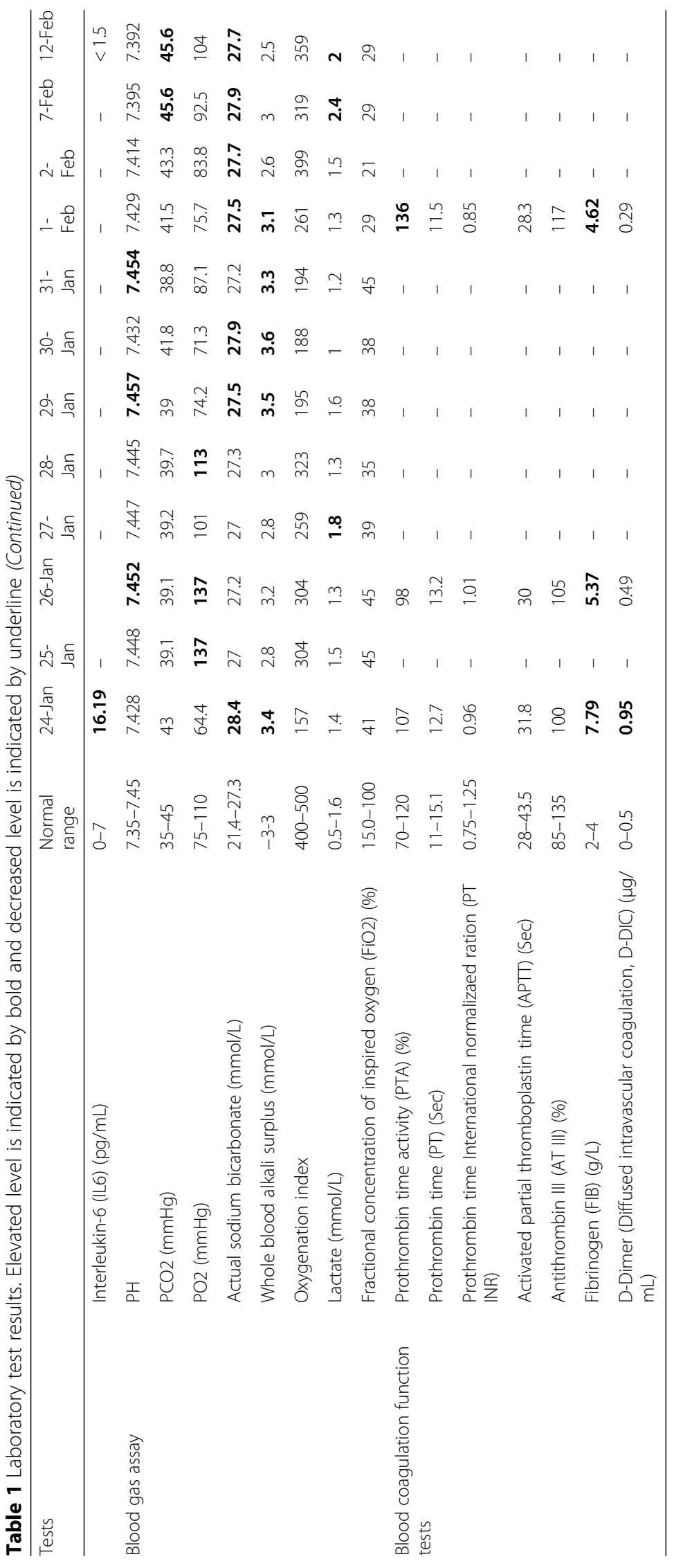


coagulation, DIC) level (Table 1) which may induce thrombus. $0.4 \mathrm{ml}$ of nadroparin calcium (ASPEN Notre Dame de Bondeville, France) subcutaneous injection was given to the patient once per day for anti-coagulation until 31 January. D-DIC level decreased to normal range at 26 January. The patient also received $40 \mathrm{mg}$ of esomeprazole sodium (AstraZeneca Pharmaceutical Co.,Ltd.) intravenous injection once per day for gastro-esophageal reflux suppression until 30 January and $30 \mathrm{mg}$ of methylprednisolone (Pfizer Manufacturing Belgium NV) intravenous injection once every $12 \mathrm{~h}$ until 28 January for anti-inflammation treatment. The increase in white blood cells (Table 1) during this period may be due to the effect of methylprednisolone. However, COVID-19 ribonucleic acid test was negative using nasopharyngeal swabs done by Shenzhen Center for Disease Control (Shenzhen CDC). Treatment scheme and viral detection time points are illustrated in Fig. 2.

From 25 January onward, the patient's syndromes had gradually resolved with only occasional dry cough. Computed tomography (CT) scan of the lungs was performed on 25th, 29th January and 12th February (Fig. 1). Evidence of severe pneumonia, including multiple lesions and swollen lymph nodes, could be seen from both of the lungs on 25th January. (Fig. 1a) The patient was then given $500 \mathrm{mg}$ lopinavir and ritonavir tablets (Abbott S.P.A., Italy) every $12 \mathrm{~h}$ until $6 \mathrm{Feb}$ as a combination treatment for antiviral effect. SARS-COV-2 ribonucleic acid test was negative using nasopharyngeal swabs done by our hospital on 26 January. To confirm the presence of SARS-COV-2, the patient's BALF sample was sent to Shenzhen CDC for viral nucleic acid detection. SARSCOV-2 ribonucleic acid was tested positive for BALF sample on 27 January. Oxygen supplement by noninvasive BIPAP was replaced by high-flow humidification oxygen therapy instrument for higher oxygen flow of 45 $\mathrm{L} / \mathrm{min}$ and oxygen concentration of $40 \%$ on 28 January. Biochemical test results indicated an increased level of alanine aminotransferase (ALT) since 29 January. The patient was diagnosed to have toxipathic hepatitis which was possibly induced by SARS-COV-2. The patient then received $50 \mathrm{mg}$ compound glycyrrhizin tablets (Akiyama Jozai Co., Ltd., Japan) three times per day from 29 January to 13 February and $50 \mathrm{mg}$ bicyclol tablets (Beijing Union Pharmaceutical Factory, China) three times per day from 31 January to 13 February for liver protection. (Figure 2) ALT level resumed to the normal range on 13 February. To prevent pulmonary fibrosis, the patient was given 7-day course of $0.2 \mathrm{~g}$ acetylcysteine granules (Bio Pharmacceutical, China) three times per day from 7 February. Obvious improvements could be seen from the subsequent CT scanning results of the lungs on 29th January (Fig. 1b) and 12 February (Fig. 1c). Oxygen supplement by high-flow humidification oxygen therapy instrument was discontinued on 31 January and the patient was given nasal catheter for oxygen inhalation
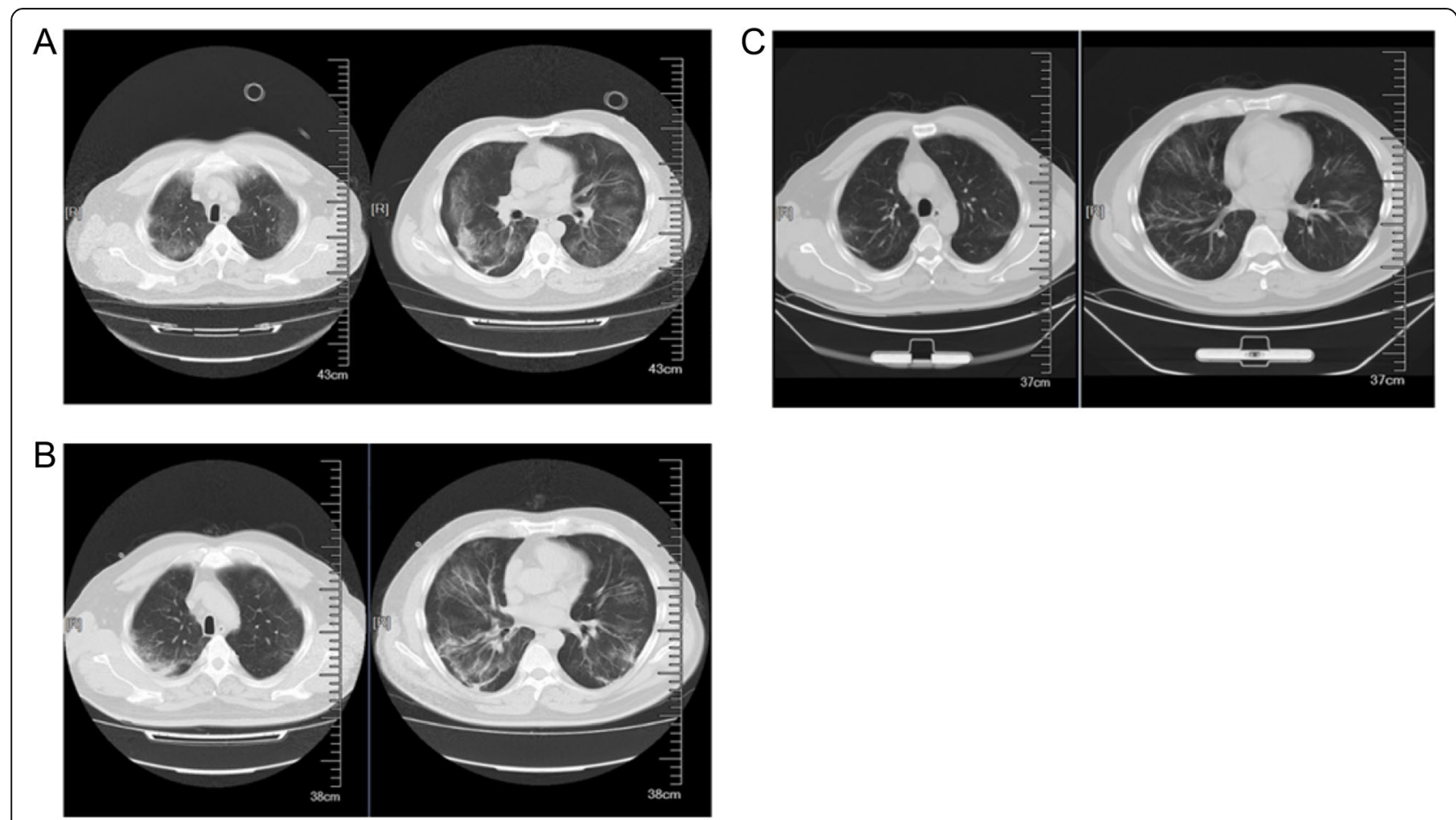

Fig. 1 CT scanning results of the lungs. a. CT scan images on 25 January. b. CT scan images on 29 January. c. CT scan images on 12 February. Improvements in abnormalities could be seen 


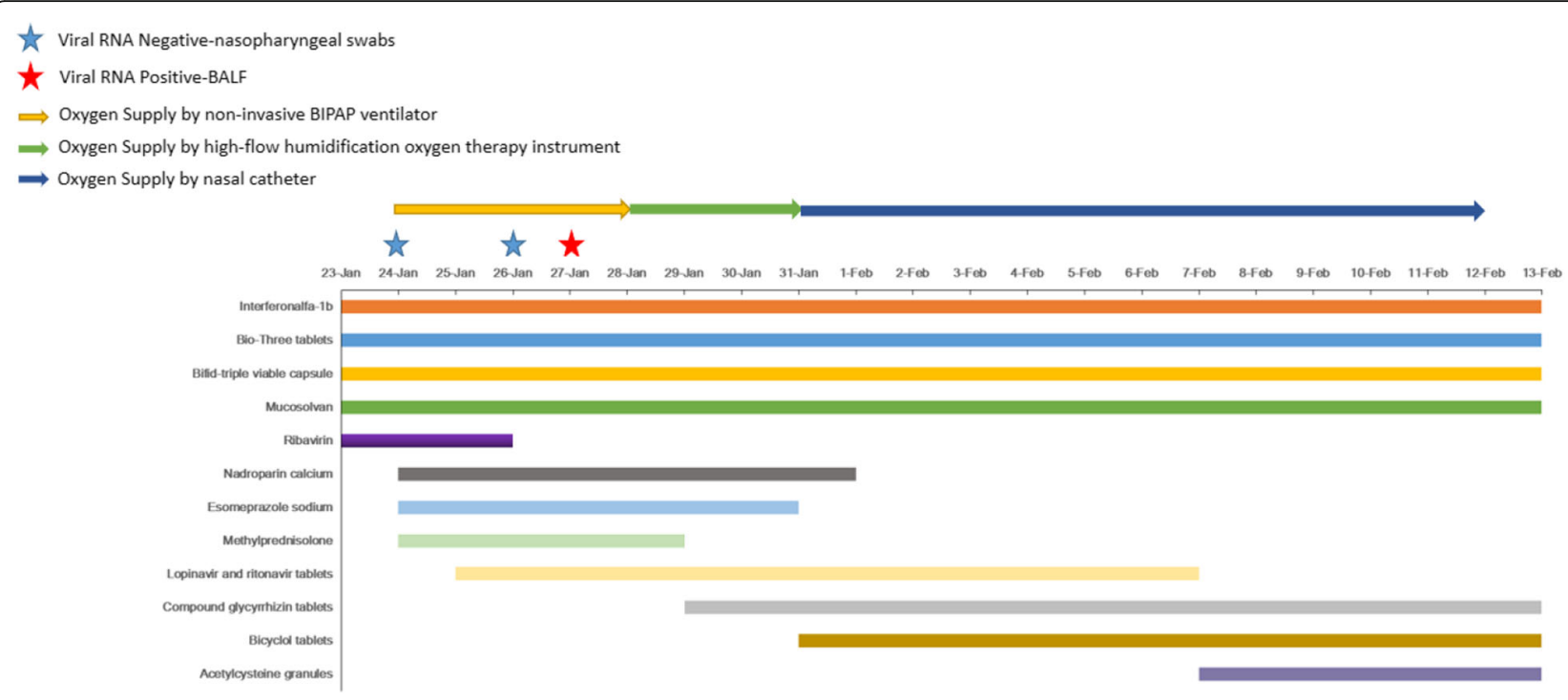

Fig. 2 Treatment schemes and Viral RNA detection time points

with a flow rate of $4 \mathrm{~L} / \mathrm{min}$. His clinical conditions was stable with fractional concentration of inspired oxygen $\left(\mathrm{FiO}_{2}\right)$ value fluctuating within the normal range. (Table 1) On 2 February, the patient stated that there was obvious improvement of his symptoms. CT scanning of the lungs (Fig. 1c) on 12 February confirmed the improvement and the patient was discharged on the following day.

\section{Discussion and conclusions}

This case report described the symptoms of a SARSCOV-2 infected patient and treatment measures taken to the patient. The patient was in close contact with a person from Wuhan and was infected through humanto-human transmission. According to the seventh edition of Novel Coronavirus Pneumonia (NCP) treatment plan issued by National Health Commission of the People's Republic of China, this patient in the case report is considered as a severely ill case of the COVID-19 pneumonia. The patient's course of disease reached 11 days which is the period of acme at the time of hospital admission and showed respiratory failure symptoms. The unconventional aspect of this case is that the detection of the patient's upper respiratory tract specimen was SARS-COV-2 negative repeatedly while that of BALF sample was positive for SARS-COV-2 virus. This suggests that the lung is possibly the main target of the SARS-COV-2 virus. We speculate that the virus migrates from upper respiratory tract to lower respiratory tract as the infection progresses, which may explain the negative test results of nasopharyngeal swabs. As reported by Dr. Yang Yang and his group, the nucleic acid of SARSCOV-2 could be detected from BALF samples of critically ill patients with COVID-19 pneumonia while not from the upper respiratory tract specimens of some patients [10]. In contrast, the detection of SARS-COV-2 RNA was positive from the upper respiratory tract specimens at mild stage of illness [11]. This indicates that the distribution of this virus in the respiratory system is closely related to the severity of the disease, and also indicates that early diagnosis is a key point to avoid false negative results when testing by direct methods. Thus, detection of SARS-COV-2 RNA in BALF samples is of great importance in confirming of the infection in the similar cases to the one described in this report. Although it is largely supportive, our treatment scheme was proven to be effective in helping the patient combating the virus. Our report highlights the importance to carry out bronchoscopy and detection of SARS-COV-2 RNA from BALF samples as complementary interventions in addition to monitoring epidemiological changes, clinical symptoms and chest CT findings of the unconventional COVID-19 pneumonia cases like the one described in this report, which will be informative and clinically significant in guiding the prognosis of the disease.

\section{Abbreviations \\ COVID-19: Coronavirus disease 2019; SARS-COV-2: Severe acute respiratory syndrome coronavirus 2; BALF: Bronchoalveolar-lavage fluid; CT: Computed tomography; BIPAP: Bilevel positive airway pressure; RSV: Respiratory syncytial virus; RNA: Ribonucleic acid; IPAP: Pressure for inhalation; EPAP: Pressure for exhalation; ESR: Erythrocyte sedimentation rate; DIC: Diffuse intravascular coagulation; CDC: Center for Disease Control; ALT: Alanine aminotransferase; $\mathrm{FiO}_{2}$ : Fractional concentration of inspired oxygen}

\section{Acknowledgments}

Not applicable.

Authors' contributions

$P Z, W W, L P, Y L 1, C C, L C, J L, M C, S F, X J$, FW, JY, LY, YL2 contributed to the clinical patient care and management. PZ and $C Z$ contributed to the 
manuscript preparation. PZ, CZ, FW and LY contributed to the data analysis. $Y L 2$ contributed to the manuscript verification. All authors have read and approved the manuscript.

\section{Funding}

This work is supported by National Science and Technology Major Project (2017ZX10103011). LY is supported by the Chinese Ministry of Education Changjiang Scholar Program (Q2018288). The funders contributed to the clinical patient care and management, and data analysis.

\section{Availability of data and materials}

All data generated or analysed during this study are included in this published article.

Ethics approval and consent to participate

This study is approved by the Ethics Committees from Shenzhen Third People's Hospital (2020-055) and the patient is consent to participate.

\section{Consent for publication}

Written informed consent for publication of the clinical details and/or clinical images was obtained from the patient.

\section{Competing interests}

The authors declare that they have no competing interests.

Received: 12 March 2020 Accepted: 20 April 2020

Published online: 30 April 2020

\section{References}

1. Huang C, et al. Clinical features of patients infected with 2019 novel coronavirus in Wuhan, China. Lancet. 2020;395(10223):497-506.

2. Zhu N, et al. A novel coronavirus from patients with pneumonia in China, 2019. N Engl J Med. 2020;382(8):727-33.

3. Centers for Disease Control and Prevention, Coronavirus Disease 2019 (COVID-19), 2020. in https://www.cdc.gov/coronavirus/2019-ncov/.

4. Benvenuto D, et al. The 2019-new coronavirus epidemic: evidence for virus evolution. J Med Virol. 2020;92(4):455-9.

5. Lam, T.T.Y., et al., Identification of 2019-nCoV related coronaviruses in Malayan pangolins in southern China. 2020: p. 2020.02.13.945485.

6. Li Q, et al. Early transmission dynamics in Wuhan, China, of novel coronavirus-infected pneumonia. N Engl J Med. 2020;382(13):1199-207.

7. Xia J, et al., Evaluation of coronavirus in tears and conjunctival secretions of patients with SARS-CoV-2 infection [published online ahead of print, 2020 Feb 26]. J Med Virol. 2020. https://doi.org/10.1002/jmv.25725.

8. Zhang, H., et al., The digestive system is a potential route of 2019-nCov infection: a bioinformatics analysis based on single-cell transcriptomes. 2020: p. 2020.01.30.927806.

9. Zhang W, et al. Molecular and serological investigation of 2019-nCoV infected patients: implication of multiple shedding routes. Emerg Microbes Infect. 2020;9(1):386-9.

10. Yang, Y., et al., Evaluating the accuracy of different respiratory specimens in the laboratory diagnosis and monitoring the viral shedding of 2019-nCoV infections. 2020: p. 2020.02.11.20021493.

11. Holshue ML, et al., First Case of 2019 Novel Coronavirus in the United States. N Engl J Med. 2020;382(10):929-36.

\section{Publisher's Note}

Springer Nature remains neutral with regard to jurisdictional claims in published maps and institutional affiliations.

Ready to submit your research? Choose BMC and benefit from:

- fast, convenient online submission

- thorough peer review by experienced researchers in your field

- rapid publication on acceptance

- support for research data, including large and complex data types

- gold Open Access which fosters wider collaboration and increased citations

- maximum visibility for your research: over $100 \mathrm{M}$ website views per year

At $\mathrm{BMC}$, research is always in progress.

Learn more biomedcentral.com/submissions 